\title{
REGISTRY OF CARDIAC PATIENTS WHO UNDERWENT CARDIAC CATHETERIZATION OR INVASIVE IMAGING PROCEDURES AT NEW CHILDREN'S HOSPITAL AIN SHAMS UNIVERSITY
}

\author{
Nevin Mohamed Mamdouh Habeeb, Marwa Waheed Abd Elhady Nasef ${ }^{1}$ and \\ Doha Osman Youssef Elsharnouby ${ }^{2}$
}

1-Pediatrics Department, Faculty of Medicine, Ain Shams University

2-Resident, ElShiekh Zayed specialized hospital - Egyptian ministry of health

Corresponding author Doha Osman Youssef Elsharnouby

Mobile: (+2) 01027627836

E.mail:

dosman@svs.edu.eg

Received: 22/4/2021

Accepted: 24/5/2021

Online ISSN: 2735-3540

\section{ABSTRACT:}

Background: Cardiac catheterization is one of the most widely performed cardiac procedures. Medical record completeness and registry is a key performance indicator that is related with delivery of healthcare services in the hospital. At hospital level, statistics derived from the daily bed census and medical records are used to assess the utilization of services and enable the hospital to make appropriate financial and administrative plans and to conduct vital research.

Aim of the Work: To do statistical analysis of patient's data who underwent cardiac catheterization to evaluate the current status, the prospects of improvements and future developments.

Patients and Methods: This cross sectional study included review of files of 389 patients who underwent cardiac catheterizations or invasive cardiac imaging procedures for diagnosis or treatment of various congenital heart diseases at the cardiac catheterization unit, new children's hospital, Ain Shams University during the period from first of January 2018 to the end of December 2019.

Results: In our study, interventional catheterization represented 191 (49.1\%) of all studied cases whereas diagnostic catheterization were 115 (29.6\%). The majority of procedures were done under general anesthesia and 8 cases (2.1\%) only were done under sedation. The most frequent interventional procedure done was PDA device closure (28.30\%). Among our study group, the number of complicated procedures was 23 procedures representing a percentage of $5.9 \%$ with desaturation being the most common complication (26.1\%) which encountered during balloon valvuloplasty operations. Mortality was recorded in only 2 patients $(0.5 \%)$. Success rate of overall procedures was $99 \%$.

Conclusion: The outcomes of the procedures done in our relatively new center were satisfactory and approximated to results of other international pediatric cardiac catheterizations centers as regards complications, mortality and success rate. Neonatal interventions were limited. Complications were higher among interventional procedures with desaturation being the most common complication which developed frequently during balloon pulmonary valvuloplasty followed by supraventricular tachycardia and arrhythmia; judicious catheter manipulation and correction of any metabolic abnormality is critical, but being prepared for such events is vital. 
Keywords: Congenital heart diseases, Cardiac catheterization, Medical registry

\section{INTRODUCTION:}

Congenital heart diseases (CHDs) occur in nearly $1 \%$ of live births. Being six times more common than chromosomal abnormalities and four times more common than neural tube defects. The incidence of CHD with intrauterine diagnosis ranges from $2.4 \%$ to $54 \%{ }^{(1)}$.

The term cardiac catheterization can be used to refer to either right heart catheterization or left heart catheterization or both. The procedure can be either diagnostic or therapeutic.

As expected, in any invasive procedure, there are some patient related and procedurerelated complications. With significant advances in the equipment used for catheterization, the improved skill of the operators, and newer techniques, the rates of these complications have been reduced significantly ${ }^{(2)}$.

Medical record completeness and registry is a key performance indicator that is related with delivery of healthcare services in the hospital. At hospital level statistics derived from the daily bed census and medical records are used to assess the utilization of services and enable the hospital to make appropriate financial and administrative plans and to conduct vital research $^{(3)}$.

Better quality of healthcare data in patient medical records can affect clinical and administrative decision making in health economics and patient safety ${ }^{(\mathbf{4})}$.

\section{AIM OF THE WORK:}

This study aims to do statistical analysis of patients data who underwent cardiac catheterization to evaluate the current status and the prospects of improvements and future developments.

\section{PATIENTS AND METHODS:}

Study population: This cross sectional study included review of files of 389 who underwent cardiac catheterizations or invasive cardiac imaging procedures for diagnosis or treatment of various congenital heart diseases to evaluate the current status and the prospects of improvements and future development. Data were collected retrospectively from the medical records of the cardiac catheterization unit, New children's hospital, Ain shams university during the period from first of January 2018 to the end of December 2019 and were meticulously revised to obtain full proper information.

Inclusion criteria: All patients who were operated upon at the cardiac catheterization unit in the 2 years period previously mentioned either for diagnostic or interventional procedures. Approval of the local ethical committee was obtained.

\section{The review included the following itmes:}

History, Examination, Significant laboratory/imaging results and Detailed procedural data (procedure type, type of sedation, vascular access, type and size of device if inserted, adverse events, discharge status and success rate )

\section{Statistical Analysis:}

Data were collected, revised, coded and entered to the Statistical Package for Social Science (IBM SPSS) version 23. The quantitative data were presented as mean, standard deviations and ranges when parametric and median, inter-quartile range (IQR) when data found non-parametric. Also qualitative variables were presented as number and percentages.

The comparison between groups regarding qualitative data was done by using Chi-square test and/or Fisher exact test 
when the expected count in any cell found less than 5 .

The comparison between two groups regarding quantitative data and non parametric distribution was done by using Mann-Whitney test.

The comparison between more than two groups regarding quantitative data and non parametric distribution was done by using Kruskall-Wallis test.

The confidence interval was set to $95 \%$ and the margin of error accepted was set to $5 \%$. So, the p-value was considered significant as the following: P-value > 0.05: Non significant (NS), P-value < 0.05: Significant
(S) and P-value < 0.01: Highly significant (HS).

\section{RESULTS:}

\section{Descriptive analysis:}

A total of 389 patients with CHD were admitted to the cardiac catheterization unit in new children's hospital during the period from first of January 2018 to the end of December 2019. Descriptive data illustrated in table 1 .

The majority of procedures were done under general anesthesia and 8 cases $(2.1 \%)$ only were done under sedation.

Table (1): Descriptive data of the studied patients:

\begin{tabular}{|l|l|c|}
\hline \multicolumn{2}{|l|}{} & No.= 389 \\
\hline \multirow{2}{*}{ Age (years) } & Median(IQR) & $4(1.5-8)$ \\
\cline { 2 - 3 } & Range & $0.01-18$ \\
\hline Neonates ( No / \% ) & 10 & $2.5 \%$ \\
\hline \multirow{2}{*}{ Sex } & Female & $200(51.4 \%)$ \\
\cline { 2 - 3 } & Male & $189(48.6 \%)$ \\
\hline \multirow{2}{*}{ Weight $(\mathrm{kg})$} & Median(IQR) & $15(9.6-24)$ \\
\cline { 2 - 3 } & Range & $2-94$ \\
\hline \multirow{2}{*}{ Height $(\mathrm{cm})$} & Median(IQR) & $100(80-125)$ \\
\cline { 2 - 3 } & Range & $50-160$ \\
\hline \multirow{2}{*}{ BMI $\left(\mathrm{Kg} / \mathrm{m}^{2}\right)$} & Mean \pm SD & $17.32 \pm 4.81$ \\
\cline { 2 - 3 } & Range & $8-38$ \\
\hline \multirow{2}{*}{ SBP $(\mathrm{mmHg})$} & Mean \pm SD & $101.45 \pm 10.2$ \\
\cline { 2 - 3 } & Range & $60-135$ \\
\hline \multirow{2}{*}{ DBP $(\mathrm{mmHg})$} & Mean \pm SD & $61.50 \pm 11.89$ \\
\cline { 2 - 3 } & Range & $25-100$ \\
\hline \multirow{2}{*}{ SPO2 $(\%)$} & Mean \pm SD & $94.41 \pm 8.24$ \\
\cline { 2 - 3 } & Range & $55-100$ \\
\hline
\end{tabular}

Age: 0.01 = 2days, SBP (Systolic Blood Pressure) DBP (Diastolic Blood Pressure), SPO2(O2 Saturation) BMI( body mass index)

Table (2): Percentage of different types of cardiac catheterization and TEE Procedures:

\begin{tabular}{|l|c|c|}
\hline \multicolumn{1}{|c|}{ Catheterization and TEE } & No. & $\%$ \\
\hline Interventional Catheterization & 191 & $49.1 \%$ \\
\hline Diagnostic Catheterization & 115 & $29.6 \%$ \\
\hline TEE & 83 & $21.3 \%$ \\
\hline Total & 389 & $100 \%$ \\
\hline
\end{tabular}

TEE (Tranesophageal Echocardiography) 
Table (3): Various vascular accesses used during cardiac catheterization procedures:

\begin{tabular}{|l|c|c|}
\hline \multicolumn{1}{|c|}{ Vascular accesses } & Total No: 306 & Total \%: $100 \%$ \\
\hline Femoral artery and vein & 157 & $51.30 \%$ \\
\hline Femoral vein & 116 & $37.90 \%$ \\
\hline Femoral artery & 29 & $9.50 \%$ \\
\hline Alternative routes of vascular access & 4 & $1.30 \%$ \\
\hline Total & 306 & $100 \%$ \\
\hline
\end{tabular}

Alternative routes of vascular access were included in 4 patients , 2 of them through axillary artery and the other 2 through radial artery . ASD (Atrial septal defect), VSD (Ventricular septal defect), PDA (Patent ductus arteriosus)

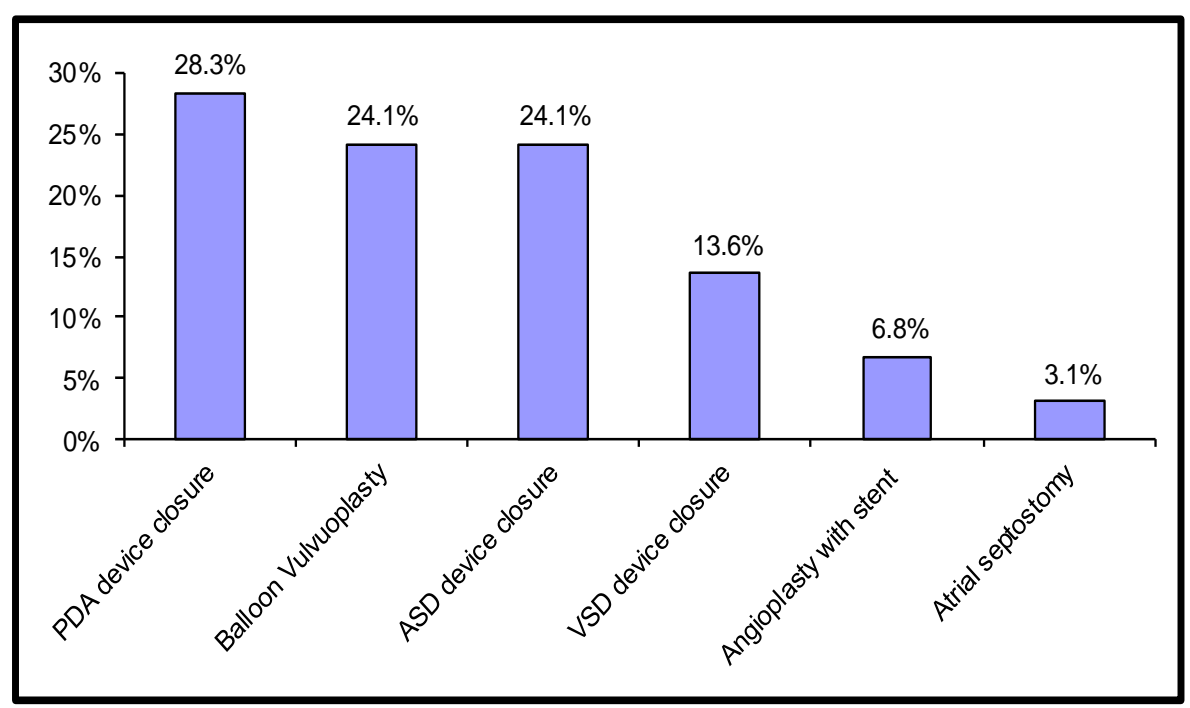

Diagram (1): Illustration of Percentages of different interventional procedures done by the study group

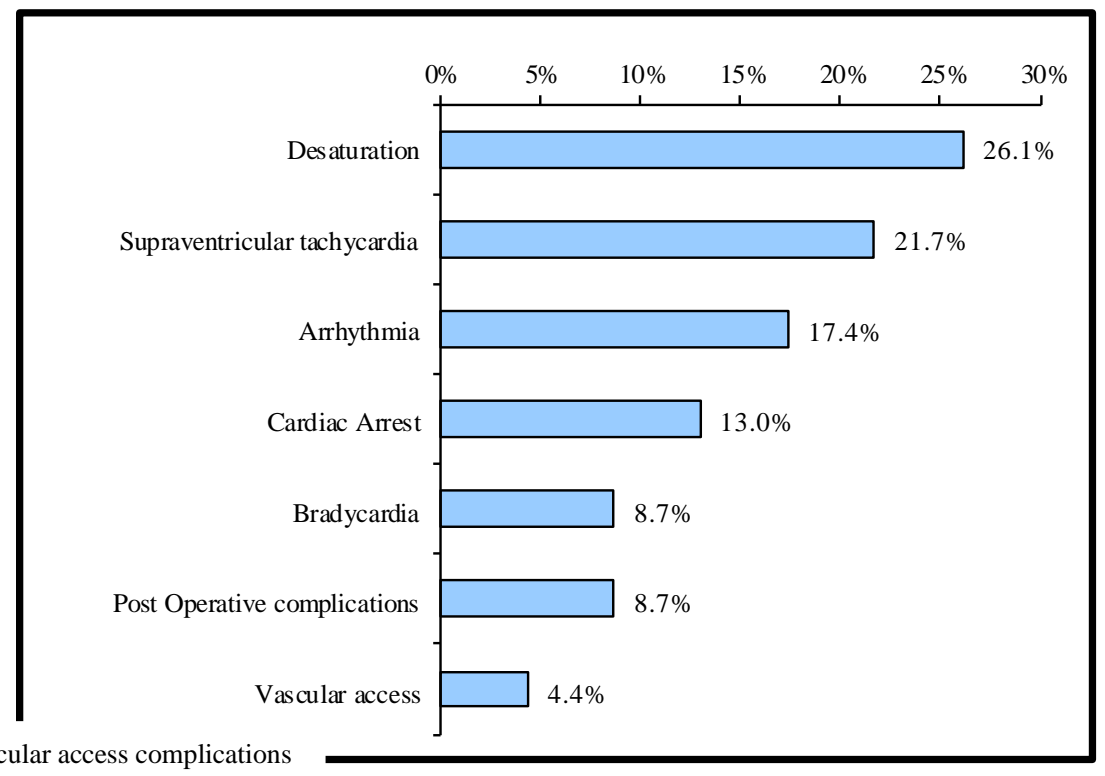

Diagram (2): Operative and post-operative complications of the studied patients. 
The overall success rate was $99 \%$. Among our studied patients 2 cases had cardiac arrest while 2 cases failed to insert a device.

\section{DISCUSSION}

Clinical registries play an important role in monitoring disease and healthcare delivery patterns and generating real world evidence of the impact of treatment and service delivery models on health outcomes ${ }^{(5)}$. Increasingly, clinical registries are being used in quality improvement projects to improve healthcare processes, adherence to clinical practice guidelines and standards; and reduce the cost of delivering care. Registries generally operate by providing details of clinical care, compliance with the evidence based guidelines and patient reported outcomes to participating hospitals and to clinicians. Such registries also play an important role in medical research. Data within registries provide an ideal platform for randomized clinical trials, reducing both time and cost of prospective data collection ${ }^{(\boldsymbol{6})}$.

Indeed, the cardiac procedure registry in Australia led to early identification of outlier performance to ensure the maintenance of cardiac care standards and benchmarking of outcome data with feedback to clinicians and hospitals. Similarly, the deployment of the National Cardiovascular Data Registry (NCDR) in the United States resulted in better monitoring of cardiac procedures, comparison of diagnostic and therapeutic patterns in different settings, and assessment of the safety and performance of medical equipment used for cardiac procedures ${ }^{(7)}$.

In the current study, we analyzed all cardiac catheterization procedures performed in our cardiac catheterization unit in new children's hospital Ain shams university by reviewing and revising the collected data from the patients medical records over a 2 year period to determine the spectrum, clinical profile and outcome of patients with congenital heart disease (CHD) admitted to our unit.

Congenital heart disease (CHD) is one of the leading causes of mortality in the first year of life ${ }^{(8)}$.

Among our studied population female to male ratio was 1.1:1, Also a study by Shah et al.,(2008) who included 84 cases of congenital heart disease in the age group below 15 years stated that female to male ratio was $1: 1.5^{(9)}$.

As regards procedure type risk categories; neonates (age less than 30 days) had a risk 6 category which is the highest among other procedure type risk categories ${ }^{(\mathbf{1 0})}$.

In our study Neonates were 10 cases only (2.5\%) 8 males and 2 females which stands with a recent study by Kamel et al., (2019) where neonatal percentage was $(2.5 \%)$ only compared to their total number of patients 1129 (11)

In our study the majority of procedures were done under general anesthesia and 8 cases only were done under sedation, which agrees with Reddy et al., (2006) in an overview of the common lesions encountered in the cardiac catheterization laboratory as regards anesthetic management of patients with congenital and acquired heart lesions as well as the procedures performed. they stated that general anesthesia is often preferable to sedation in cardiac catheterization procedures as it provides more physiologically stable conditions, patients toleration of the procedure is improved, contemporary standards require a second operator to manage sedation and the cases are anatomically and physiologically more complex and hence the procedure may last longer ${ }^{(12)}$.

A recent study by Kamel et al., (2019) conducted on a total of 1129 patients admitted to cardiac catheterization unit over 1 year period with median age of 4 years old stated that as regards anesthesia, general anesthesia $(91.1 \%)$ was the main stay of most of the procedures, 90 cases $(8 \%)$ were done under IV 
sedation and only 10 cases $(0.9 \%)$ was under local anesthesia ${ }^{(\mathbf{1 1})}$.

As regards vascular access utilized for different procedures we found that the most common vascular access was combined femoral arterial and venous access 157 cases $(51.3 \%)$ with the majority of them; 90 cases (78.3\%) underwent diagnostic catheterization and only 4 patients had alternative routes of vascular access(ARVA) (2.1\%) all of them underwent interventional catheterization.

A study by Kumar et al., (2014) included 300 consecutive diagnostic cardiac catheterization performed since April 2007. Children who underwent cardiac catheterization ranged in weight from $1.6 \mathrm{~kg}$ to $35 \mathrm{~kg}$, with their age range 0 day-12 years, stated that combined vascular access (Arterial and venous access) was obtained for all their patients after puncturing right or left femoral artery and vein by Seldinger's technique which stands with our study ${ }^{(13)}$.

Among these cardiac catheterization procedures; $29(9.50 \%)$ procedures were performed via femoral arterial access.

In this study, the number of interventional catheterizations was 191 cases $(49.1 \%)$ of total catheterization procedures that were done over the 2 years period and the main indication for intervention was PDA closure 54 cases (28.30\%) followed by balloon vulvuoplasty 46 cases $(24.10 \%)$ and ASD closure 46 cases (24.10\%).

In a study by Qawasmeh et al., (2018) done at Queen Alia Heart Institute, on a total of 574 patients; males (42\%) with (mean age of 9 years) who underwent interventional cardiac catheterization revealed a great resemblance between their study and ours regarding the common types of interventional cardiac procedures done which was as follow; PDA closure 200 patients $(35 \%)$ followed by ASD closure 153 patients $(27 \%)$ and balloon vulvuoplasty 115 patients $(20 \%)^{(\mathbf{1 4})}$.

The overall complication rate reported in our study was (5.9\%) out of 23 cases; 21 cases
(91.3\%) had operative complications and 2 cases $(8.7 \%)$ had post-operative complications. Minor complications occurred in 15 cases (3.8\%). The most common complication was desaturation $(26.1 \%)$ which happened during balloon valvuoplasty operations followed by supraventricular tachycardia $(21.7 \%)$ and arrhythmia $(17.4 \%)$ and the least was vascular access complications (4.4\%).Complications were higher in interventional procedures, while none occurred during TEE. Among our study group mortality rate represented $0.5 \%$ in a total of 389 patients.

A study by Lee et al., (2016) on a total 2071 cardiac catheterizations with median age of 5.5 years reported overall complication rate was $16.2 \%$. In their study, the incidence of severe complications was only $1.15 \%$ and the mortality rate was only $0.19 \%$. The complication rates were higher in the interventional group than the diagnostic and hemodynamic catheterization group ${ }^{(\mathbf{1 5})}$.

In a more recent study by Kamel et al., (2019) conducted on a total of 1129 patients with a median age of 4 years old stated that the overall complication rate in their study was $10.5 \%$ including major, minor and mortality cases. Their main complications were minor complications representing $7.8 \%$ of all study population and mortality rate was about $0.5 \%^{(11)}$.

Among our studied patients, our overall success rate was $99 \%$.Cardiac arrest was reported in 2 cases while 2 cases failed to insert a device which goes with a study by $\boldsymbol{C} . \boldsymbol{H}$. Lin et al., (2014) of a large multicenter experience with life threatening events in congenital cardiac catheterization, the authors reported a low incidence of life threatening events $(2.1 \%)$ and mortality $(0.28 \%)$ despite the complexity of diseases and procedures. The predictors of life threatening events were < 1year, increased hemodynamic vulnerability, and high procedure complexity ${ }^{(\mathbf{1 6})}$.

The higher percentage of complications in other studies may relate to the large number of 
patients, more technically different procedures done and more neonatal interventions.

\section{Conclusion:}

The outcomes of the procedures done in our relatively new center were satisfactory and approximated to results of other international pediatric cardiac catheterizations centers as regards complications, mortality and success rates . Neonatal interventions were limited. Complications were higher among interventional procedures with desaturation being the most common complication which developed frequently during balloon pulmonary valvuloplasty followed by supraventricular tachycardia and arrhythmia; judicious catheter manipulation and correction of any metabolic abnormality is critical, but being prepared for such events is vital.

\section{Recommendations:}

Preparations for cardiac catheterization should be done to maximize the patient's safety, that represent the doctor's main target. So, adequate preparations of the patient before the procedure and careful monitoring during the procedure can minimize complications and fatality from invasive studies, and achieve a pleasing procedure outcome.

\section{REFERENCES:}

1. Midan MF, Alsheemy RI, Eid SM, Abdel Salam ME (2016): Efficacy of fetal echocardiography in prenatal diagnosis of congenital heart diseases. Int $\mathrm{J}$ Reprod Contracept Obstet Gynecol.; 5(5):15531557.

2. Manda YR, Hollinger I, Mittnacht A (2018): Cardiac catheterization laboratory: catheterization, interventional cardiology, and ablation techniques for children. Int. Anesthesiol. Clin. 47(3):63-99.

3. Liebler, J.G. and McConnell, C.R. (2020): Management principles for health professionals. Jones \& Bartlett Publishers.

4. Hydari, M.Z., Telang, R. and Marella, W.M. (2019): Saving patient Ryan-can advanced electronic medical records make patient care safer?. Management Science, 65(5), pp.2041-2059.

5. Gliklich RE, Dreyer NA, Leavy MB. (2014): Registries for evaluating patient outcomes: a user's guide. $3^{\text {rd }}$ Ed: Agency for Health Care Research and Quality.

6. Hoque, D.M.E., Kumari, V., Hoque, M., Ruseckaite, R., Romero, L. and Evans, S.M. (2017): Impact of clinical registries on quality of patient care and clinical outcomes: a systematic review. PloS one, 12(9), e0183667.

7. Tabrizi, A.T., Moghaddasi, H., Rabiei, R., Sharif-Kashani, B. and Nazemi, E. (2019): Development of a catheteri-zation and percutaneous coronary intervention registry with a data management approach: a systematic review. Perspectives in health informa-tion management, 16 (Winter).

8. Slitine, N.E.I., Bennaoui, F., Sable, C.A., Martin, G.R., Hom, L.A., Fadel, A., Moussaoui, S., Inajjarne, N., Boumzebra, D., Mouaffak, Y. and Younous, S. (2020): Pulse oximetry and congenital heart disease screening: Results of the first pilot study in Morocco. International journal of neonatal screening, 6(3).

9. Shah, G.S., Singh, M.K., Pandey, T.R., Kalakheti, B.K. and Bhandari, G.P. (2008): Incidence of congenital heart disease in tertiary care hospital. Kathmandu Univ Med $J(K U M J), 6(1), 33-36$.

10. Jayaram, N., Spertus, J.A., O'Byrne, M.L., Chan, P.S., Kennedy, K.F., Bergersen, L. and Glatz, A.C. (2017): Relationship between hospital procedure volume and complications following congenital cardiac catheterization: a report from the IMproving Pediatric and Adult Congenital Treatment (IMPACT) registry. American heart journal, 183, 118-128.

11. Kamel, H., Nour, A., Shams, K.A. and Roushdy, A.M., (2019): Pediatric Cardiac Catheterization Outcome-A Single Center Experience. $J$ Cardiovasc Dis Diagn, 7(375), 2.

12. Reddy, K., Jaggar, S. and Gillbe, C. (2006): The anaesthetist and the cardiac 
catheterisation laboratory. Anaesthesia, 61(12), 1175-1186.

13. Kumar, P., Joshi, V.S. and Madhu, P.V. (2014): Diagnostic pediatric cardiac catheterization: Experience of a tertiary care pediatric cardiac centre. medical journal armed forces india, 70(1), 10-16.

14. Qawasmeh, Y., Hijazi, I., Altarawneh, H., Almomani, A. and Abu Haweleh, A. (2018): Interventional cardiac catheterization In Congenital Heart Disease: Experience at Queen Alia Heart Institute. JRMS, 25(2), 64-67.
15. Lee, K.E., Seo, Y.J., Kim, G.B., An, H.S., Song, Y.H., Kwon, B.S., Bae, E.J. and Noh, C.I. (2016): Complications of cardiac catheterization in structural heart disease. Korean circulation journal, 46(2), 246-255.

16. C.H. Lin, S. Hegde, A.C. Marshall, D. Porras, K. Gauvreau. (2014): Incidence and management of life-threatening adverse events during cardiac catheterization for congenital heart disease, pediatr Cardiol, 35 (1), pp. 140-148. 


\section{تسجيل بيانات مرضى القلب الخاضعين لعمليات قسطرة القلب أو إجراعات التصوير الجراحي في

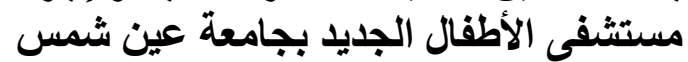 \\ نيفين تحمد ممدوح حبيب، مروه وحيا عبد الهادي ناصف , ضحي عثمان يوسف الثرنوبي

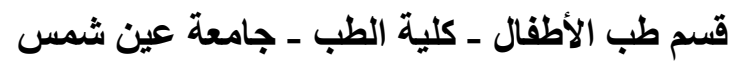

المقدمة: تعد قسطرة القلب من أكثر العمليات أداءً على نطاق واسع. فقي الو لايات المتحدة يتم إجر اء أكثر من مليون عملية

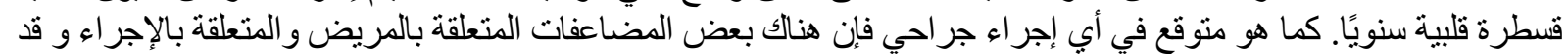

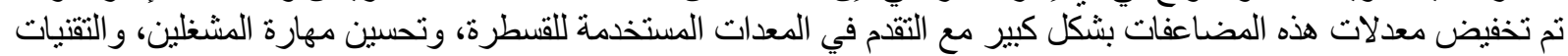

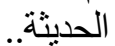

الهذف من البحث: إجراء تحليل إحصائي للمرضى الذين خضعوا لقسطرة قلبية لتقييم الوضع الحالي وآفاق التحسينات و التطور ات المستقبلية.

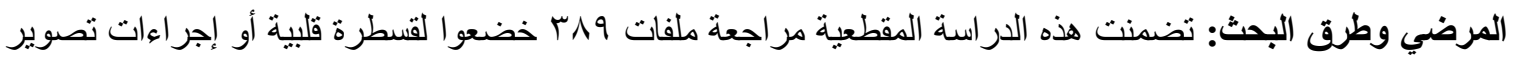

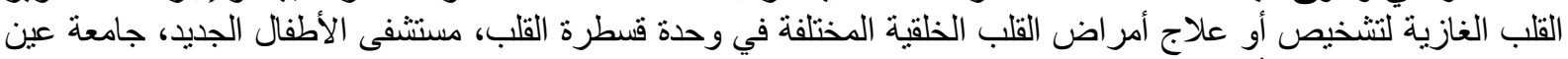

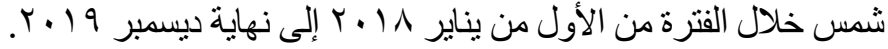

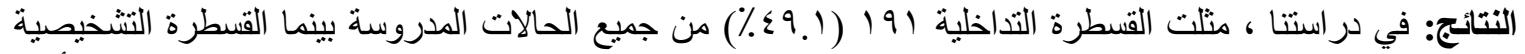

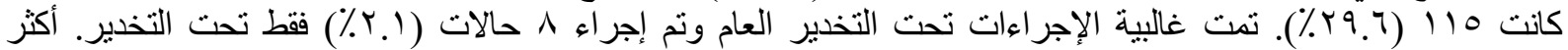

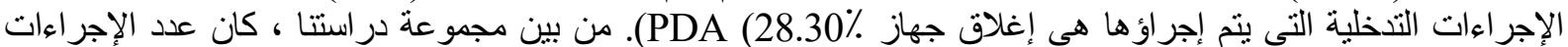

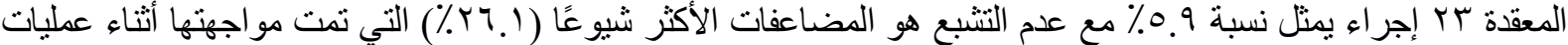

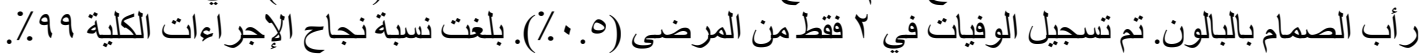

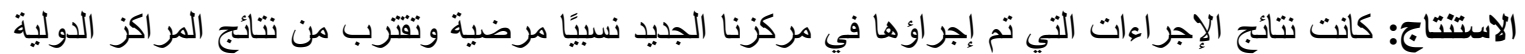

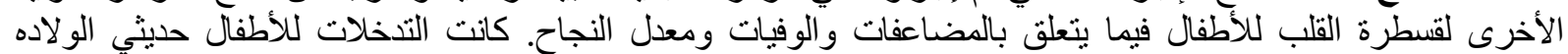

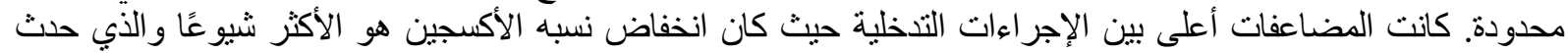

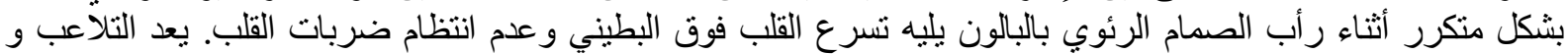
تحريك القسطرة بحكمه وتصحيح أي خلل في التمثيل الغذائي أمرًا بالغ الأهية ، ولكن الاستعداد لمثل هذه الأحداث أمر حيوي. 